\title{
Selection of Host Differentials for Elucidating Pathogenic Variation in Magnaporthe grisea Populations Adapted to Finger Millet (Eleusine coracana)
}

Talluri Kiran Babu, Acharya N. G. Ranga Agricultural University (ANGRAU), Rajendranagar, Hyderabad 500030, Telangana, India; and International Crops Research Institute for the Semi-Arid Tropics (ICRISAT), Patancheru, Hyderabad 502324, Telangana, India; Rajan Sharma and R. P. Thakur, ICRISAT, Telangana, India; Hari D. Upadhyaya, ICRISAT, Telangana, India; Department of Agronomy, Kansas State University, Manhattan 66506; and The UWA Institute of Agriculture, The University of Western Australia, Crawley WA 6009, Australia; P. Narayan Reddy, ANGRAU, Telangana, India; and A. G. Girish, ICRISAT, Telangana, India

\begin{abstract}
Babu, T. K., Sharma, R., Thakur, R. P., Upadhyaya, H. D., Reddy, P. N., and Girish, A. G. 2015. Selection of host differentials for elucidating pathogenic variation in Magnaporthe grisea populations adapted to finger millet (Eleusine coracana). Plant Dis. 99:1784-1789.

Blast, caused by Pyricularia grisea (teleomorph: Magnaporthe grisea), is the most devastating disease of finger millet affecting production, utilization, and trade in Africa and Southeast Asia. An attempt was made to select a set of putative host differentials that can be used to determine virulence diversity in finger-millet-infecting populations of $M$. grisea. Thus, a differential set comprising eight germplasm accessions selected from finger millet core collection (IE 2911, IE 2957, IE 3392, IE 4497, IE 5091, IE 6240, IE 6337, and IE 7079) and a resistant ('GPU 28') and a susceptible ('VR 708 ') variety was developed. This differential set was used to study

pathogenic variation in 25 isolates of $M$. grisea collected from Karnataka, Telangana, and Andhra Pradesh states in India. Based on the reaction (virulent $=$ score $\geq 4$ and avirulent $=$ score $\leq 3$ on a 1-to- 9 scale) on host differentials, nine pathotypes were identified among $25 \mathrm{M}$. grisea isolates. Pathotype 9, represented by isolate $\mathrm{Pg} 23$ from Vizianagaram, was the most virulent because it could infect all of the host differentials except GPU 28. This study will be helpful in devising strategies for monitoring virulence change in $M$. grisea populations, and for identification of blast resistance in finger millet for use in disease resistance breeding programs.
\end{abstract}

Finger millet (Eleusine coracana (L.) Gaertn.) is a nutrient-rich staple food and the world's fourth-ranked millet crop after sorghum, pearl millet, and foxtail millet. The crop generates income for millions of poor people in the semiarid regions of Eastern and Southern Africa, as well as South Asia. The precise estimate of area and production of finger millet at the global level is not available because the crop is frequently reported with other millets, including pearl millet, in the Food and Agriculture Organization database. It has been estimated that finger millet accounts for $12 \%$ of global millet area and is cultivated in more than 25 countries in Africa and Asia. The major producers are Uganda, India, Nepal, and China (http://www.icrisat. org/crop-fingermillet.htm). In India, finger millet ranks next to pearl millet and is cultivated on an area of 2 million ha with annual production of 2.15 million tons (Apoorva et al. 2010), and nearly $60 \%$ of the area is in Karnataka state (Nagaraja et al. 2012). Finger millet is primarily cultivated for grain; however, it is also a valuable source of fodder. Wide adaptability to varied agroclimatic conditions, developmental plasticity, high nutritive value, and excellent storage qualities of finger millet make it suitable for ensuring food security (Mgonja et al. 2007). Finger millet is a promising source of micronutrients and protein, and can contribute to the alleviation of iron, zinc, and protein malnutrition in women and preschool children in African and Southeast Asian countries (Underwood 2000; Upadhyaya et al. 2011). Thus, finger millet plays a key role in the livelihood of smallholder farmers in the semiarid areas of Africa and Asia.

During the past three decades, the most significant achievement in finger millet improvement in India is the use of African germplasm in hybridization programs (Gowda et al. 1986) that resulted in the development and release of several high-yielding varieties. Though the use of African germplasm has contributed significantly to the increased finger

Corresponding author: R. Sharma; E-mail: r.sharma@cgiar.org

Accepted for publication 4 June 2015.

http://dx.doi.org/10.1094/PDIS-10-14-1089-RE

(C) 2015 The American Phytopathological Society millet productivity in India, diseases and insect pests in addition to abiotic stress pose a continuous threat to the successful realization of high productivity of finger millet. Among diseases that affect finger millet, blast caused by Pyricularia grisea Sacc. (teleomorph: Magnaporthe grisea (T. T. Hebert) M. E. Barr) is the most devastating and widespread disease that causes substantial grain and forage yield losses. The yield loss due to blast has been reported to be over 25\% (Nagaraja et al. 2007) and, in certain areas, reduction in grain yield could be as high as $76 \%$ (Ramappa et al. 2006). The disease affects the crop at all growth stages from seedling to grain formation; however, panicle blast is the most destructive form of the disease (Takan et al. 2012).

The disease can be best managed through host plant resistance because the crop is predominantly grown by resource-poor farmers who cannot afford other methods of disease control such as using expensive chemical fungicides. However, resistance breakdown is a big challenge in managing blast disease through host plant resistance. This is mainly due to variability in $M$. grisea, rapid selection of virulence against specific host cultivars, and less exposure of breeding material to a full range of virulence present in the pathogen populations (Zeigler et al. 1995). Most of the resistance genes in rice break down in a few years because of their race specificity and the rapid change in pathogenicity of the blast fungus (Suh et al. 2009). Although substantial work has been done in the rice-blast pathosystem (Zeigler et al. 1995), limited information is available for the finger millet-blast pathosystem (Babu et al. 2013; Takan et al. 2012). Pathogenic variation among $M$. grisea populations adapted to rice, wheat, pearl millet, foxtail millet, and other weed hosts has been reported (Kang and Lee 2000; Nakayama et al. 2005; Prabhu et al. 1992; Sharma et al. 2002; Sharma et al. 2013, 2014). Although efforts have been made to study genetic diversity and aggressiveness of the pathogen populations (Babu et al. 2013; Takan et al. 2012), there is no information available on the virulence diversity in finger-millet-infecting populations of M. grisea. Limited information on the finger millet-blast pathosystem has stalled efforts toward development and deployment of blastresistant cultivars adapted to different agroecological conditions. Therefore, it is important to elucidate pathogenic diversity in the finger-millet-infecting populations of the pathogen for devising a cost-effective management strategy. The aim of this study was to 
identify host differentials and examine virulence diversity in $M$. grisea isolates collected from major finger-millet-growing states in India.

\section{Material and Methods}

Collection and maintenance of isolates. Blast-infected samples (leaf, neck, and finger) of finger millet were collected from farmers' fields and finger millet blast disease nursery conducted at Vizianagaram and Nandyal in Andhra Pradesh, Mandya and Nagenahalli in Karnataka, and Patancheru in Telangana states in India during 2008 to 2010 rainy seasons (Table 1). Isolations of $25 \mathrm{M}$. grisea isolates collected from the above mentioned locations were made from the blast-infected tissue on oatmeal agar medium ( $50 \mathrm{~g}$ of rolled oat, $15 \mathrm{~g}$ of agar, and 1 liter of distilled water) at the International Crops Research Institute for the Semi-Arid Tropics, Patancheru, Telangana, India. After incubating the cultures at $25 \pm 1{ }^{\circ} \mathrm{C}$ for 10 to 15 days, a dilute spore suspension $(3 \times$ $10^{3}$ spores $\mathrm{ml}^{-1}$ ) of each isolate was prepared in sterilized distilled water and plated onto $4 \%$ water agar in petri plates. After 10 to $12 \mathrm{~h}$ of incubation, single germinating conidia were selected under a microscope, picked up with a sterilized inoculation needle, and placed individually in test tubes containing oatmeal agar. Thus, monoconidial cultures of $25 \mathrm{M}$. grisea isolates from finger millet were established and maintained on oatmeal agar medium for further studies.

Host differentials. Twenty-six accessions from the core collection that had shown resistant or differential reactions in the finger millet blast resistance stability nursery (FMBRSN) when evaluated under field conditions at five locations Patancheru, Vizianagaram, Nandyal, Mandya, and Nagenahalli in India during 2009 and 2010 rainy seasons (Babu 2011) were selected for further screening under greenhouse conditions. These 26 accessions and two cultivars, 'GPU 28 ' (resistant) and 'VR 708' (susceptible), were screened for blast reaction against 5 of the $25 \mathrm{M}$. grisea isolates (Pg01, Pg20, Pg33, $\mathrm{Pg} 42$, and Pg55; one isolate each from the above mentioned locations) used for the pathogenic variability study. Based on the disease reaction (resistant or susceptible) to the selected five isolates under greenhouse conditions, the 28 finger millet lines (26 core accessions and two checks) were clustered into seven distinct groups (Fig. 1).
Finally, 10 genotypes, eight core accessions (IE 2911, IE 2957, IE 3392, IE 4497, IE 5091, IE 6240, IE 6337, and IE 7079), and two cultivars (GPU 28 and VR 708) representing the seven groups were selected as host differentials to elucidate virulence diversity in M. grisea populations adapted to finger millet.

Inoculum preparation and inoculation. Inoculum of each of the $25 \mathrm{M}$. grisea isolates was multiplied on oatmeal agar plates by incubating the inoculated plates at $25^{\circ} \mathrm{C}$ for 7 to 10 days. Spores were harvested by flooding the plates with sterilized distilled water and scraping the growth by a spatula. A spore suspension of each isolate was filtered through two layers of sterilized muslin cloth and the spore count was adjusted to $1 \times 10^{5}$ spore $\mathrm{ml}^{-1}$ using a hemocytometer. A drop of Tween 20 (surfactant) was added to the suspension to ensure uniform dispersal of the spores.

Seed of the host differential lines were sown in 15-cm-diameter pots filled with sterilized soil-sand-farm yard manure mix $(2: 1: 1$ by volume) and placed in a greenhouse bay maintained at $30 \pm 1^{\circ} \mathrm{C}$. Pot-grown seedlings ( 12 days old) were spray inoculated with an aqueous conidial suspension of each isolate, covered with polyethylene bags, and incubated in an incubation chamber at $23 \pm 1^{\circ} \mathrm{C}$ for $48 \mathrm{~h}$. Two pots of each of the 10 differentials, with 10 seedlings per pot, were inoculated with each of the 25 isolates of M. grisea. After $48 \mathrm{~h}$ of incubation, the bags were removed and the plastic pots containing inoculated finger millet plants were transferred to a greenhouse bay and exposed to high humidity ( $>90 \%$ relative humidity) and leaf wetness for 7 days. Blast severity on each plant was assessed 10 days after inoculation using a 1-to-9 progressive rating scale, where $1=$ no lesion to small brown specks of pinhead size; 2 = larger brown specks; 3 = small, roundish to slightly elongated, necrotic gray spots, approximately 1 to $2 \mathrm{~mm}$ in diameter, with a brown margin; 4 = typical blast lesions, usually confined to the area between main veins, covering $\leq 5 \%$ of the leaf area; $5=$ typical blast lesions covering 6 to $10 \%$ of the leaf area; $6=$ typical blast lesions covering 11 to $25 \%$ of the leaf area; $7=$ typical blast lesions covering 26 to $50 \%$ of the leaf area; $8=$ typical blast lesions covering 51 to $75 \%$ of the leaf area and many leaves dead; and $9=$ all leaves dead. Isolates with

Table 1. Origin of 25 isolates of Magnaporthe grisea used in the pathogenic variability study

\begin{tabular}{|c|c|c|c|c|}
\hline \multirow[b]{2}{*}{ Isolate number } & \multirow[b]{2}{*}{ Year ${ }^{\mathbf{a}}$} & \multicolumn{3}{|c|}{ Origin } \\
\hline & & Cultivar & Plant part & Place of collection (location, state) \\
\hline $\operatorname{Pg} 01$ & 2008 & VL 149 & Neck & ICRISAT, Patancheru, Telangana \\
\hline $\operatorname{Pg} 03$ & 2008 & IE 518 & Finger & ICRISAT, Patancheru, Telangana \\
\hline $\mathrm{Pg} 04$ & 2009 & IE 588 & Neck & ICRISAT, Patancheru, Telangana \\
\hline Pg05 & 2009 & IE 2322 & Finger & ICRISAT, Patancheru, Telangana \\
\hline Pg09 & 2009 & IE 3038 & Neck & ICRISAT, Patancheru, Telangana \\
\hline Pg14 & 2009 & VL 149 & Neck & Vizianagaram, Andhra Pradesh \\
\hline $\operatorname{Pg} 19$ & 2009 & IE 501 & Neck & Vizianagaram, Andhra Pradesh \\
\hline $\operatorname{Pg} 20$ & 2008 & IE 1299 & Neck & Vizianagaram, Andhra Pradesh \\
\hline $\operatorname{Pg} 23$ & 2009 & IE 3470 & Finger & Vizianagaram, Andhra Pradesh \\
\hline $\operatorname{Pg} 25$ & 2008 & IE 4759 & Neck & Vizianagaram, Andhra Pradesh \\
\hline $\operatorname{Pg} 28$ & 2009 & IE 501 & Neck & Nandyal, Andhra Pradesh \\
\hline Pg30 & 2009 & IE 588 & Finger & Nandyal, Andhra Pradesh \\
\hline $\operatorname{Pg} 31$ & 2008 & IE 3270 & Neck & Nandyal, Andhra Pradesh \\
\hline $\operatorname{Pg} 33$ & 2009 & IE 4545 & Neck & Nandyal, Andhra Pradesh \\
\hline $\operatorname{Pg} 35$ & 2008 & IE 5788 & Leaf & Nandyal, Andhra Pradesh \\
\hline Pg39 & 2009 & MR 6 & Neck & Mandya, Karnataka \\
\hline $\mathrm{Pg} 40$ & 2009 & IE 518 & Finger & Mandya, Karnataka \\
\hline $\mathrm{Pg} 42$ & 2008 & IE 2790 & Neck & Mandya, Karnataka \\
\hline $\mathrm{Pg} 43$ & 2009 & IE 3470 & Finger & Mandya, Karnataka \\
\hline $\operatorname{Pg} 47$ & 2009 & IE 6337 & Node & Mandya, Karnataka \\
\hline $\mathrm{Pg} 48$ & 2009 & MR 6 & Leaf & Nagenahalli, Karnataka \\
\hline Pg50 & 2009 & IE 2572 & Leaf & Nagenahalli, Karnataka \\
\hline Pg51 & 2010 & IE 2572 & Neck & Nagenahalli, Karnataka \\
\hline Pg54 & 2009 & IE 6154 & Leaf & Nagenahalli, Karnataka \\
\hline Pg55 & 2010 & IE 6154 & Neck & Nagenahalli, Karnataka \\
\hline
\end{tabular}

a Year of collection.

${ }^{\mathrm{b}}$ Locations in India; ICRISAT = International Crops Research Institute for the Semi-Arid Tropics 
a score $\leq 3.0$ on a host differential were considered avirulent, while those showing a score $\geq 4.0$ (typical blast lesions) were considered virulent (Sharma et al. 2013). For the confirmation of disease reaction (compatible or incompatible), the differentials were reevaluated against $M$. grisea isolates.

Data analysis. A binary matrix of virulence data of all of the isolates based on their disease reaction on host genotypes was constructed by coding avirulent reactions (score $\leq 3.0$ on a 1 -to- 9 scale) as 0 and virulent reactions (score $\geq 4.0$ ) as 1 (Sharma et al. 2013). Binary matrices were then analyzed using a numerical taxonomy system (NTSYS-pc, version 2.2; Exeter Biological Software, Setauket, NY). The proximity matrix was computed using the simple matching similarity coefficient and a dendrogram was constructed by unweighted pair-group method with arithmetic averages using the sequential agglomerative hierarchical nested cluster analysis module for classification of the genotypes into different groups based on the reaction against five isolates (Fig. 1), and grouping of isolates into pathogenic groups or pathotypes (Fig. 2) based on the reaction on 10 host differential lines (Rohlf 2005).

\section{Results}

Selection of host differentials. The 28 finger millet lines were clustered into seven distinct groups based on their disease reaction

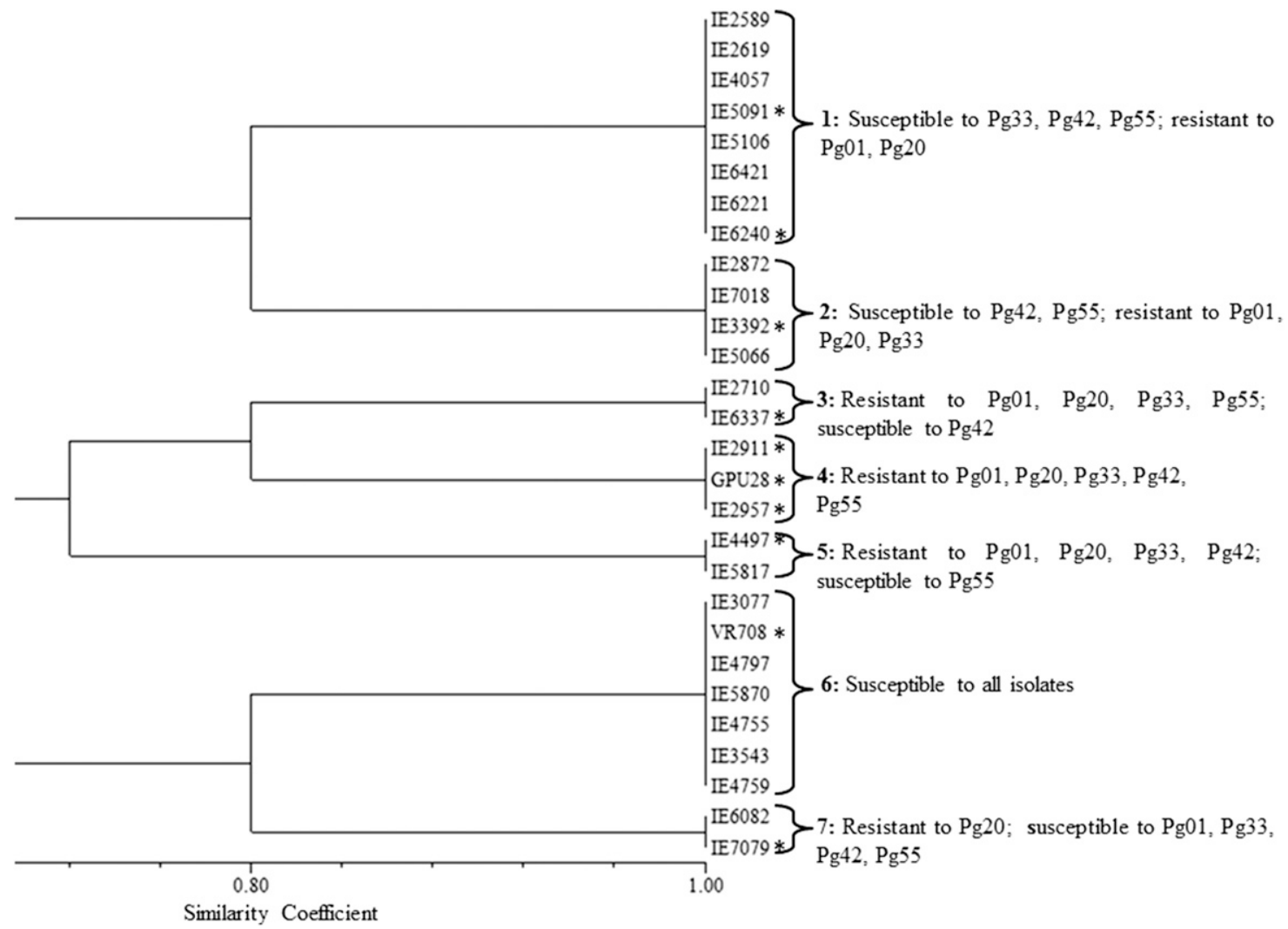

Fig. 1. Selection of host differentials based on the reaction of 26 core accessions and two varieties of finger millet to five isolates of Magnaporthe grisea. Asterisks (*) indicate genotype selected as host differential.

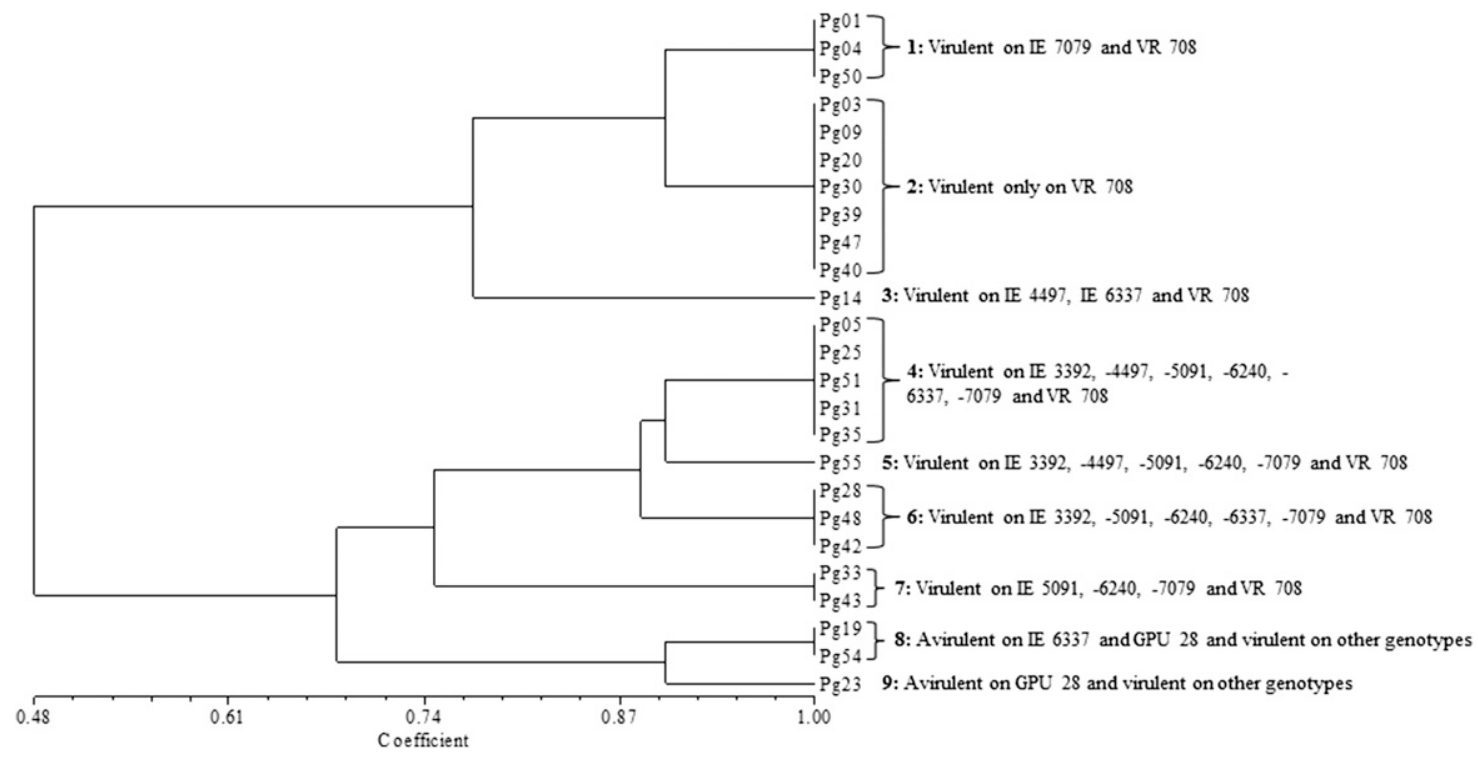

Fig. 2. Pathogenic groups of Magnaporthe grisea based on the reaction of 25 isolates on finger millet host differentials. 
(resistant or susceptible) to the selected five $M$. grisea isolates ( $\mathrm{Pg} 01$, Pg20, Pg33, Pg42, and Pg55; Fig. 1). Group 1, consisting of eight accessions (IE 2589, 2619, 4057, 5091, 5106, 6421, 6221, and 6240 ), exhibited an incompatible and resistant reaction ( $\leq 3.0$ score) to $\mathrm{Pg} 01$ and $\mathrm{Pg} 20$ but a compatible reaction ( $\geq 4.0$ score) to $\mathrm{Pg} 33$, $\mathrm{Pg} 42$, and Pg55. Group 2 included four accessions (IE 2872, 7018, 3392, and 5066) having compatible reactions to isolates Pg42 and $\mathrm{Pg} 55$ and incompatible reactions to isolates Pg01, Pg20, and Pg33. Group 3 consisted of two accessions (IE 2710 and IE 6337) with incompatible reactions to $\mathrm{Pg} 01, \mathrm{Pg} 20, \mathrm{Pg} 33$, and Pg55 and compatible reactions to Pg42. Three accessions (IE 2911, IE 2957, and GPU 28) were resistant ( $\leq 3.0$ score) to all five isolates and were clustered in group 4. Group 5, represented by IE 4497 and IE 5817, was incompatible to $\mathrm{Pg} 01, \mathrm{Pg} 20, \mathrm{Pg} 33$, and $\mathrm{P} 42$ and compatible to Pg55. Group 6 included seven accessions showing compatible reactions to all five isolates. Group 7, consisting of two accessions (IE 6082 and IE 7079), recorded incompatible reactions to Pg20 and compatible reactions to Pg01, Pg33, Pg42, and Pg55. Two accessions (IE 5091 and IE 6240) from group 1; one each from group 2 (IE 3392), group 3 (IE 6337), group 5 (IE 4497), group 6 (VR 708), and group 7 (IE 7079); and all three accessions (IE 2911, IE 2957, and GPU 28) from group
4 were selected to develop a set of host differentials. Thus, eight accessions (IE 2911, 2957, 3392, 4497, 5091, 6240, 6337, and 7079) and a resistant (GPU 28) and susceptible (VR 708) cultivar representing the seven groups were selected as host differentials to elucidate virulence diversity in $M$. grisea populations adapted to finger millet. All the core accessions included in the differential set are of African origin, except IE 2957, which is from Germany (Table 2). GPU 28 and VR 708 are the released varieties for cultivation on farmers' fields in India.

Pathogenic variability. All the isolates induced blast symptoms on the susceptible variety VR 708, indicating a reliable disease screen. Large variation was observed in the disease scores (on a 1-to-9 scale) on host differentials against the pathogen isolates (Table 3). Differences were also observed for the mean blast scores of host differentials against isolates as well as for the isolates across differentials. The mean blast severity across differentials was maximum (score 6.2) for isolate Pg23 collected from Vizianagaram, Andhra Pradesh followed by Pg51 (score 5.6) from Nagenahalli, Karnataka. Minimum severity (score 2.5) was recorded for Pg47 from Mandya, Karnataka and Pg30 from Nandyal, Andhra Pradesh (Table 3). As expected, the mean blast score across isolates was maximum

Table 2. Origin, race type, and alternate identity of finger millet core accessions and varieties selected as host differentials

\begin{tabular}{|c|c|c|c|c|}
\hline Host differentials & Country of origin & Race & Subrace & Alternate identity \\
\hline IE 2911 & Zambia & Vulgaris & Incurvata & ZM 676; EC 138417 \\
\hline IE 2957 & Germany & Vulgaris & Liliacea & EC 140211 \\
\hline IE 3392 & Zimbabwe & Compacta & $\ldots$ & TGR 1599;EC 153319 \\
\hline IE 4497 & Zimbabwe & Vulgaris & Digitata & AMM 224 \\
\hline IE 5091 & Zimbabwe & Vulgaris & Digitata & SDFM 313 \\
\hline IE 6240 & Zimbabwe & Vulgaris & Incurvata & AMM 41 \\
\hline IE 6337 & Zimbabwe & Vulgaris & Incurvata & AMM 965 \\
\hline IE 7079 & Kenya & Vulgaris & Liliacea & SDFM 1987; 18816 \\
\hline GPU $28^{a}$ & India & Vulgaris & $\ldots$ & $\ldots$ \\
\hline VR $708^{a}$ & India & Vulgaris & $\ldots$ & $\ldots$ \\
\hline
\end{tabular}

a Released varieties.

Table 3. Leaf blast severity caused by 25 isolates of Magnaporthe grisea on host differentials

\begin{tabular}{|c|c|c|c|c|c|c|c|c|c|c|c|}
\hline \multirow[b]{2}{*}{ Isolate } & \multicolumn{10}{|c|}{ Leaf blast severity (1-to-9 scale) ${ }^{a}$} & \multirow[b]{2}{*}{ Mean } \\
\hline & IE 2911 & IE 2957 & IE 3392 & IE 4497 & IE 5091 & IE 6240 & IE 6337 & IE 7079 & GPU 28 & VR 708 & \\
\hline Pg01 & 1.1 & 1.5 & 1.8 & 2.5 & 2.2 & 1.2 & 1.7 & 4.0 & 3.0 & 8.0 & 2.7 \\
\hline Pg03 & 1.4 & 3.0 & 2.2 & 2.5 & 2.3 & 2.8 & 2.2 & 2.4 & 2.9 & 7.4 & 2.9 \\
\hline Pg04 & 2.2 & 3.0 & 2.5 & 3.0 & 2.2 & 3.0 & 2.1 & 4.4 & 2.7 & 7.1 & 3.2 \\
\hline Pg05 & 1.7 & 3.0 & 5.0 & 4.6 & 4.2 & 7.5 & 4.7 & 4.4 & 3.0 & 7.8 & 4.6 \\
\hline Pg09 & 1.9 & 2.1 & 2.9 & 2.3 & 2.3 & 3.0 & 1.9 & 3.0 & 3.0 & 7.7 & 3.0 \\
\hline Pg14 & 2.5 & 2.0 & 2.3 & 4.0 & 2.0 & 3.0 & 4.5 & 2.9 & 1.6 & 7.0 & 3.2 \\
\hline $\operatorname{Pg} 19$ & 4.0 & 4.0 & 5.5 & 7.7 & 4.0 & 6.5 & 2.5 & 6.5 & 3.0 & 7.0 & 5.1 \\
\hline Pg20 & 1.8 & 2.0 & 3.0 & 2.2 & 2.5 & 3.0 & 3.0 & 2.1 & 2.5 & 7.5 & 3.0 \\
\hline $\operatorname{Pg} 23$ & 4.8 & 4.8 & 9.0 & 5.7 & 8.0 & 7.2 & 4.0 & 7.5 & 2.3 & 9.0 & 6.2 \\
\hline $\operatorname{Pg} 25$ & 3.0 & 2.9 & 4.5 & 5.5 & 6.1 & 7.7 & 4.8 & 5.9 & 2.3 & 7.7 & 5.0 \\
\hline $\operatorname{Pg} 28$ & 2.9 & 1.8 & 4.0 & 3.0 & 5.5 & 5.3 & 5.5 & 4.0 & 2.0 & 7.9 & 4.2 \\
\hline Pg30 & 1.4 & 1.3 & 3.0 & 2.0 & 1.9 & 2.2 & 2.4 & 2.1 & 1.4 & 7.2 & 2.5 \\
\hline $\operatorname{Pg} 31$ & 2.2 & 2.0 & 5.5 & 4.0 & 7.7 & 5.2 & 5.5 & 4.7 & 3.0 & 7.1 & 4.7 \\
\hline $\operatorname{Pg} 33$ & 2.2 & 2.1 & 2.8 & 2.2 & 4.4 & 5.0 & 2.5 & 7.5 & 2.3 & 7.3 & 3.8 \\
\hline $\operatorname{Pg} 35$ & 3.0 & 3.0 & 7.3 & 6.6 & 5.3 & 8.0 & 7.0 & 4.0 & 2.0 & 7.6 & 5.4 \\
\hline $\operatorname{Pg} 39$ & 2.5 & 2.5 & 2.3 & 3.0 & 2.7 & 2.5 & 2.1 & 2.0 & 1.1 & 7.0 & 2.8 \\
\hline $\operatorname{Pg} 40$ & 2.0 & 3.0 & 2.0 & 2.0 & 2.0 & 3.0 & 2.0 & 3.0 & 1.0 & 7.4 & 2.7 \\
\hline $\operatorname{Pg} 42$ & 3.0 & 3.0 & 4.6 & 3.0 & 4.1 & 5.8 & 5.9 & 5.2 & 2.8 & 7.2 & 4.5 \\
\hline $\mathrm{Pg} 43$ & 2.6 & 2.3 & 2.0 & 1.8 & 4.0 & 6.6 & 3.0 & 4.5 & 1.6 & 7.0 & 3.5 \\
\hline $\operatorname{Pg} 47$ & 1.7 & 1.8 & 1.0 & 1.7 & 2.0 & 3.0 & 2.3 & 3.0 & 1.3 & 7.3 & 2.5 \\
\hline $\operatorname{Pg} 48$ & 2.5 & 2.5 & 4.2 & 3.0 & 5.1 & 7.3 & 5.0 & 6.3 & 2.5 & 8.3 & 4.7 \\
\hline Pg50 & 2.7 & 2.2 & 2.9 & 3.0 & 2.8 & 2.7 & 3.0 & 4.2 & 2.0 & 7.2 & 3.3 \\
\hline $\operatorname{Pg} 51$ & 3.0 & 2.5 & 7.2 & 6.6 & 7.7 & 7.5 & 6.0 & 5.4 & 2.5 & 7.5 & 5.6 \\
\hline $\operatorname{Pg} 54$ & 4.5 & 4.0 & 6.3 & 5.2 & 8.0 & 8.5 & 3.0 & 4.2 & 2.5 & 7.5 & 5.4 \\
\hline Pg55 & 3.0 & 3.0 & 7.3 & 4.3 & 5.5 & 5.2 & 3.0 & 5.4 & 3.0 & 7.8 & 4.8 \\
\hline Mean & 2.5 & 2.6 & 4.0 & 3.7 & 4.2 & 4.9 & 3.6 & 4.3 & 2.3 & 7.5 & $\ldots$ \\
\hline
\end{tabular}

a Mean of two pots, 10 seedlings per pot. 
(score 7.5) on the susceptible VR 708 included in the differential set. A minimum mean blast score of 2.3 was observed on GPU 28 across isolates, followed by IE 2911 (score 2.5) and IE 2957 (score 2.6).

Based on the reaction of isolates (avirulent or virulent) on the host differentials, 25 isolates were grouped into nine pathogenic groups or pathotypes (Fig. 2). Pathotype 9, represented by isolates Pg23 from Vizianagaram, was the most virulent because it could infect all of the host genotypes tested in this study except GPU 28. Pathotype 8, represented by $\operatorname{Pg} 19$ and $\operatorname{Pg} 54$, was avirulent ( $\leq 3.0$ score) on IE 6337 and GPU 28 and virulent on the other eight genotypes. Pathotype 2, represented by seven isolates (Pg03, Pg09, Pg20, Pg30, Pg39, $\mathrm{Pg} 40$, and $\mathrm{Pg} 47$ ), was least virulent and could infect only susceptible VR 708, and pathotype 1 was virulent only on IE 7079 and VR 708. Pathotype 4 was virulent on seven genotypes, whereas pathotypes 5 and 6 could infect 6 of the 10 differentials (Fig. 2). Virulence of pathotypes 5 and 6 was differentiated by their reaction on IE 4497 and IE 6337. Pathotype $3(\operatorname{Pg} 14)$ and pathotype 7 were virulent on three and four differential lines, respectively.

Multiple-pathotype resistance. Among host differentials, GPU 28 showed resistance ( $\leq 3.0$ score) to all 25 isolates (nine pathotypes) of $M$. grisea. Of the eight core accessions included in the differential set, IE 2911 and IE 2957 were resistant to 22 isolates representing seven pathotypes (Table 3 ). Other accessions were resistant to 8 to 15 isolates. VR 708 was found highly susceptible to all nine pathotypes, with a score $\geq 7.0$.

\section{Discussion}

The prime objective of this study was to elucidate pathogenic variability in the M. grisea populations adapted to finger millet. Pathogenic variation in pathogen populations is determined through their reaction on host differentials. Differential hosts are sets of plant cultivars used to distinguish pathotypes (races) by their qualitative differences in their reactions (resistant or incompatible and susceptible or compatible) to different isolates of the pathogen (Sharma et al. 2013). However, differential hosts of finger millet to differentiate pathogenic variation in $M$. grisea populations are not available. Therefore, an attempt was made to select finger millet genotypes that could be used as host differentials to assess pathogenic variation in M. grisea populations. Initially, 26 germplasm accessions were selected from the core collection that had shown resistant or differential reactions in the FMBRSN evaluated at five locations (Patancheru, Vizianagaram, Nandyal, Mandya, and Nagenahalli) in India during rainy seasons in 2009 and 2010. All of the sites (except Patancheru) are located in the major finger-millet-growing regions of India and are hot spots for the evaluation of germplasm and breeding lines for blast resistance (AICSMIP 2012). However, to reduce the number of accessions to a manageable level, these 26 accessions were further evaluated against five isolates of $M$. grisea (one each from the above locations) along with two released varieties (GPU 28 and VR 708) under greenhouse conditions. Based on the reaction to five isolates of $M$. grisea, these 28 finger millet lines were clustered in seven groups. The clustering of 28 genotypes into different groups helped in the selection of genotypes to develop a set of host differentials. Group 1 included the maximum number of accessions, eight; thus, two accessions (IE 5091 and IE 6240) were selected from this group, whereas only one accession each was selected from groups $2,3,5$, and 7. Group 4 had accessions that were resistant to all five isolates; thus, all three accessions (IE 2911, IE 2957, and GPU 28) were selected from this group. Susceptible VR 708, clustered along with six susceptible accessions in group 6, was also selected. Thus, 10 genotypes (IE 2911, IE 2957, IE 3392, IE 4497, IE 5091, IE 6240, IE 6337, IE 7079, GPU 28, and VR 708) were selected as host differentials that could be used to study virulence diversity in $M$. grisea populations adapted to finger millet.

An assessment of the pathogenic variability of the 25 isolates of $M$. grisea collected from major finger-millet-growing states in India led to the identification of nine pathogenically distinct groups or pathotypes. In a similar study, Takan et al. (2012) tested the pathogenicity of $31 \mathrm{M}$. oryzae isolates from East Africa on eight finger millet varieties: E11, P665, INDAF 5, SEREMI 1, SEREMI 2, SEREMI 3,
PESE1, and GULU E. However, they could reveal differences only in the aggressiveness of $M$. oryzae populations associated with finger millet blast and not the cultivar incompatibility. Our study resulted in the identification of pathotypes of $M$. grisea showing differential (compatible or incompatible) reaction on finger millet genotypes. Differential hosts have been used to differentiate variation in $M$. grisea populations adapted to other hosts. Sharma et al. (2002) classified 119 isolates of $M$. grisea infecting rice from the northwestern Himalayan regions into 52 pathotypes on the basis of disease reaction on international rice differentials. Similarly, Sharma et al. (2013) used a differential set of 10 pearl millet genotypes to classify $25 \mathrm{M}$. grisea isolates collected from different states in India into five pathotypes. Many races have been identified in $M$. grisea infecting rice, and this variability has been cited as the principal cause for the frequent breakdown of resistance in rice varieties (Suh et al. 2009). Therefore, it is important to monitor change in the virulence spectrum of $M$. grisea populations in the major cropgrowing areas. This study will be helpful in monitoring virulence of finger-millet-infecting populations of $M$. grisea, and in the selection of resistance sources for use in blast-resistance breeding programs.

The variation in the virulence of isolates from the same location to specific accessions under controlled conditions indicates existence of intrapopulation variability (Silva et al. 2009). The results of this study clearly demonstrated the existence of more than one pathotype at one location. For instance, among the five isolates from Mandya, three isolates (Pg39, $\mathrm{Pg} 40$, and $\mathrm{Pg} 47)$ represented pathotype 2 and remaining two represented pathotype $6(\mathrm{Pg} 42)$ and pathotype $7(\mathrm{Pg} 43)$. Similarly, isolates collected from other locations were grouped in different pathogenic groups or pathotypes. Evidence also exists for the intrapopulation variability in the pathogenicity of monoconidial cultures of P. oryzae from single lesions (Bonman et al. 1987). The migration of pathotypes within the same field from one phenological stage to the other is quite common in the M. oryzae-rice pathosystem (Chen et al. 1995; Silva et al. 2009). Under such conditions, it is essential to deploy multiple-pathotype resistance in the crop cultivars. The fact that GPU 28 is resistant to blast over time in different states of India, as well as its lineage-wide resistance to $M$. grisea populations, suggests that resistance in GPU 28 is relatively stable (Nagaraja et al. 2008). In the present study as well, it was found to be resistant to all nine pathotypes of $M$. grisea. We could also identify two germplasm accessions (IE 2911 and IE 2957) having resistance to seven of the nine pathotypes of M. grisea in India. Therefore, these accessions are potential sources of multiple-pathotype resistance for use in finger millet breeding for blast resistance.

In conclusion, results of this study confirm the existence of different pathotypes of $M$. grisea adapted to finger millet in India. Multiplepathotype-resistant accessions identified in this study could be used in breeding programs to develop blast-resistant finger millet varieties. The present study provides insight into the pathogenic diversity in finger-millet-infecting populations of $M$. grisea, and has laid a foundation for monitoring virulence change in the pathogen populations and forming a framework for future resistance breeding for the management of finger millet blast in India.

\section{Acknowledgments}

We thank the BMZ/GTZ project on "Sustainable conservation and utilization of genetic resources of two underutilized crops-finger millet and foxtail millet- to enhance productivity, nutrition and income in Africa and Asia" for the financial support to carry out this research.

\section{Literature Cited}

AICSMIP. 2012. Annual report. All India Coordinated Small Millets Improvement Project, Indian Council of Agricultural Research, GKVK, Bangalore, Karnataka, India.

Apoorva, K. B., Prakash, S. S., Rajesh, N. L., and Nandini, B. 2010. STCR approach for optimizing integrated plant nutrient supply on growth, yield and economics of finger millet (Eleusine coracana (L.) Garten.). EJBS 4:19-27.

Babu, T. K. 2011. Epidemiology, virulence diversity and host-plant resistance in blast (Magnaporthe grisea (Hebert) Barr.) of finger millet (Eleusine coracana (L.) Gaertn.). Ph.D. thesis, Acharya N. G. Ranga Agricultural University, India. 
Babu, T. K., Sharma, R., Upadhyaya, H. D., Reddy, P. N., Deshpande, S., Senthilvel, S., Sarma, N. D. R. K., and Thakur, R. P. 2013. Evaluation of genetic diversity in Magnaporthe grisea populations adapted to finger millet using simple sequence repeats (SSRs) markers. Physiol. Mol. Plant Pathol. 84:10-18.

Bonman, J. M., Vergel de Dios, T. I., Bandong, J. M., and Lee, E. J. 1987. Pathogenic variability of monoconidial isolates of Pyricularia oryzae in Korea and in the Philippines. Plant Dis. 71:127-130.

Chen, D., Zeigler, R. S., Leung, H., and Nelson, R. J. 1995. Population structure of Pyricularia grisea at two screening sites of Philippines. Phytopathology 85: 1011-1020.

Gowda, B. T. S., Seetharam, A., Vishwanath, S., and Sannegowda, S. 1986. Incorporation of blast resistance to Indian elite finger millet cultivars from African cultivar IE 1012. SABRO J. 18:119-120.

Kang, S., and Lee, Y. H. 2000. Population structure and race variation of the rice blast fungus. Plant Pathol. J. 16:1-8.

Mgonja, M. A., Lenne, J. M., Manyasa, E., and Sreenivasaprasad, S. 2007. Finger millet blast management in East Africa: Creating opportunities for improving production and utilization of finger millet. In: Proc. First Int. Finger Millet Stakeholder Workshop, Nairobi, Kenya. International Crops Research Institute for the Semi-Arid Tropics, Patancheru, Greater Hyderabad, India.

Nagaraja, A., Gowda, J., Krishnappa, M., and Krishne Gowda, K. T. 2008. GPU 28: A finger millet variety with durable blast resistance. J. Mycopathol. Res. 46: 109-111.

Nagaraja, A., Jagadish, P. S., Ashok, E. G., and Krishne Gowda, K. T. 2007. Avoidance of finger millet blast by ideal sowing time and assessment of varietal performance under rainfed production situations in Karnataka. J. Mycopathol. Res. 45:237-240.

Nagaraja, A., Kumar, B. T., Raguchander, T., Hota, A. K., Patro, T. S. S. K., Gowda, D. P., Savita, E., and Gowda, M. V. C. 2012. Impact of disease management practices on finger millet blast and grain yield. Indian Phytopathol. 65:356-359.

Nakayama, H., Nagamine, T., and Hayashi, N. 2005. Genetic variation of blast resistance in foxtail millet (Setaria italica (L.) P. Beauv.) and its geographic distribution. Genet. Resour. Crop Evol. 52:863-868.

Prabhu, A. S., Filippi, M. C., and Castro, N. 1992. Pathogenic variation among isolates of Pyricularia grisea infecting rice, wheat, and grasses in Brazil. Trop. Pest Manage. 38:367-371.

Ramappa, H. K., Ravishankar, C. R., and Prakash, P. 2006. Epidemiology and integrated approach for the management of blast disease of Finger millet (Eleusine coracana) in Southern Karnataka. Pages 64-67 in: Proc. Third Natl. Semin. Millets Res. Dev. Future Policy Options in India, Vol. III: Small
Millets. K. T. Krishnegowda, N. Seetharama, I. S. Khairwal, Vilas A Tonapi, S. Ravikumar, B. Jayaramegowda, and K. V. Raghavendra Rao, eds. All India Coordinated Sorghum Improvement Project, National Research Centre for Sorghum, Rajendranagar, Hyderabad, Andhra Pradesh, India.

Rohlf, F. J. 2005. NTSYS-pc: Numerical Taxonomy and Multivariate Analysis System Version 2.2. Exeter Software, Setauket, NY.

Sharma, R., Girish, A. G., Upadhyaya, H. D., Humayun, P., Babu, T. K., Rao, V. P., and Thakur, R. P. 2014. Identification of blast resistance in a core collection of foxtail millet germplasm. Plant Dis. 98:519-524.

Sharma, R., Upadhyaya, H. D., Manjunatha, S. V., Rai, K. N., Gupta, S. K., and Thakur, R. P. 2013. Pathogenic variation in the pearl millet blast pathogen, Magnaporthe grisea and identification of resistance to diverse pathotypes. Plant Dis. 97:189-195.

Sharma, T. R., Chauhan, R. S., Singh, B. M., Sagar, V., Paul, R., and Rathour, R. 2002. RAPD and virulence analyses of Magnaporthe grisea rice populations from north- western Himalayan region of India. J. Phytopathol. 150:649-656.

Silva, G. B., Prabhu, A. S., Filippi, M. C. C., Trindade, M. G., Araujo, L. G., and Zambolim, L. 2009. Genetic and phenotypic diversity of Magnaporthe oryzae from leaves and panicles of rice in commercial fields in the State of Goias, Brazil. Trop. Plant Pathol. 34:71-76.

Suh, J. P., Roh, J. H., Cho, Y. C., Han, S. S., Kim, Y. G., and Jena, K. K. 2009. The $\mathrm{Pi} 40$ gene for durable resistance to rice blast and molecular analysis of $\mathrm{Pi} 40$ advanced backcross breeding lines. Phytopathology 99:243-250.

Takan, J. P., Chipili, J., Muthumeenakshi, S., Talbot, N. J., Manyasa, E. O., Bandyopadhyay, R., Sere, Y., Nutsugah, S. K., Talhinhas, P., Hossain, M., Brown, A. E., and Sreenivasaprasad, S. 2012. Magnaporthe oryzae populations adapted to finger millet and rice exhibit distinctive patterns of genetic diversity, sexuality and host interaction. Mol. Biotechnol. 50: $145-158$.

Underwood, R. A. 2000. Overcoming micronutrient deficiencies in developing countries: Is there a role for agriculture? Food Nutr. Bull. 21:356-360.

Upadhyaya, H. D., Ramesh, S., Sharma, S., Singh, S. K., Varshney, S. K., Sarma, N. D. R. K., Ravishankar, C. R., Narasimhudu, Y., Reddy, V. G., Sahrawat, K. L., Dhanalakshmi, T. N., Mgonja, M. A., Parzies, H. K., Gowda, C. L. L., and Singh, S. 2011. Genetic diversity for grain nutrients contents in a core collection of finger millet (Eleusine coracana (L.) Gaertn.) germplasm. Field Crops Res. 121:42-52.

Zeigler, R. S., Cuoc, L. X., Scott, R. P., Bernardo, M. A., Chen, D., Valent, B., and Nelson, R. J. 1995. The relationship between phylogeny and virulence in Pyricularia grisea in the Philippines. Phytopathology 85:443-451. 